\title{
Effects of Applying PBL in Nursing Students' Learning English
}

\author{
Mei-Hsin $\mathrm{Ho}^{1},{ }^{*}$ Chia-Hao Chang ${ }^{1}$, Wei-Chieh Wayne $\mathrm{Yu}^{2}$ \\ ${ }^{1}$ Chang Gung University of Science \& Technology, Taiwan \\ ${ }^{2}$ Mississippi State University, USA \\ * Corresponding Author: Mei-Hsin HO \\ 59624917@163.com
}

Keywords: PBL, nursing students, English teaching

\begin{abstract}
Problem-based Learning (PBL) is a teaching and learning approach to achieve knowledge growth through problem-solving. This paper firstly gives the concept of PBL, then expounds the process of PBL in nursing students' English learning, and finally elaborates the good results of promoting nursing students' learning, such as arousing students' learning interest, improving English ability, expanding communication channels and promoting oral English teaching reform to provide some references for the relative researchers.
\end{abstract}

\section{Concept of PBL}

Problem-based Learning (PBL) is a problem oriented teaching and learning method, which is centered by students. This teaching method was invented by Barrows who was a Neurology professor in the McMaster University in Canada first in 1969. After more than 40 years of continuous improvement and development has become a more popular international teaching method, but also gradually become a new trend in the reform of medical education in china. The theoretical basis of PBL teaching mode is Piaget's constructivism learning theory. Learning is not a process of passive absorption of repeated practice and reinforcement of memory. PBL is based on the information processing psychology and cognitive psychology. It belongs to the category of constructivist learning theory, and is the core idea that is widely used in the teaching reform of constructivism.

The advantage of PBL is to cultivate students' self-learning ability by allowing students to explore the issue positively and voluntarily. It also can cultivate students' learning attitude and perseverance through the systematic learning process. Students are required to discuss the in-depth study of the problem, to the problem of critical thinking and encourage them to high levels of thinking; in the learning process, improve students on the topic of knowledge; make them master and apply the knowledge and skills of information technology; and also encourage collaboration and learning among students, improve the students' ability of expression and communication skills. PBL accords with the theory of multiple intelligences, which accords with the cognitive law of the students' language learning. It can mobilize every student's positive thinking and active input. In the solution of the problems in the process of goal setting is generally slightly higher than the actual level of the students, therefore, to students with challenging; students with greater autonomy, so as to stimulate students' interest, cultivate the sense of innovation and solving practical problems ability. PBL is a new teaching method, but it does not exclude other teaching methods. On the contrary, PBL is suitable for different teaching methods and teaching materials.

\section{Process of PBL in Nursing Students English Learning}

In practice, the PBL theory is often used in the medical English teaching. In fact, I applied the PBL theory in nursing English learning last year. The process is divided into the following three stages.

Design Learning Problems. Learning process is a dynamic process of discovering the problem. The designed problem creates a kind of "disharmony" between the content of the teaching material 
and the students' knowledge, and introduces the students into the thinking of the problem. PBL teaching method is the core of the problem, students get knowledge through solving the problem. The setting of the problem is the necessary precondition for the smooth development of the teaching method. Teachers should not only be in line with the teaching objectives, but also should be inspired and open, so as to stimulate students' enthusiasm and initiative, so that students are willing to think and explore. Combined with PBL and multimedia to provide more potential problems in a variety of settings: teachers make use of the network platform to release the problem is no longer just a single text, can also be more vivid and intuitive video, sound, and multimedia forms. The problem will no longer be time and space constraints, can at any time through the network without delay spread to the hands of students. For example, teachers can upload a registering English video about a week in advance in teaching the nursing English "registration" to let students discuss the video. Teachers can design problems like "what result in the phenomenon?" or "What can a medical staff do for the patients?" These problems can improve the learning enthusiasm of the students.

Solving Learning Problems. Students can share the information found in the library or internet to elaborate their own views in the classroom teaching. Due to the different perspective of the individual, the solution to the problem is not the same and there is more than one method which can solve the problem. Students in this process can get a variety of solutions to the same problem. This ideological collision can broaden students' vision, improve the ability to analyze and solve problems. In the analysis of the problem, teachers need to change their own role in a timely manner, from the teaching of knowledge to solve the problem of the guide. The students are the main body of learning. We need to pay attention to is that under the new environment of English teaching, to students' autonomous learning as the center, not the abolition of the role of teachers, but the teachers role requirements higher, as teachers should spend more energy to consulting and monitoring on the key and difficult grasping. Teachers should inspire and guide students to explore the answers to the questions to help students to master the basic knowledge of nursing English, improve the ability of English application. Initial plan will have some deficiencies, which requires the students in class to seriously study the basic knowledge and make use of all resources, such as the Internet and library to access relevant information, questions and answers, then back to the group to report on their findings. Everyone discusses the amendment of the initial solution and the form the final written report. Students can get the knowledge of related fields and improve the ability to analyze problems and solve problems through PBL.

Evaluate Learning Results. At this stage, each student is required to submit a report on the results of the study and each group of students has to report the research results for presentation. After the demonstration, the group accepts other students and teachers to ask questions, the members of the team to do additional answers. Teachers should actively involve, reports on more general review of and make the best use of the circumstances, summarize the subject related to knowledge. The aim of language testing is provide a scientific testing tool, the language ability of students are objective and fair evaluation, reflect the strengths and weaknesses of teaching and for improving the practice teaching, to improve teaching quality. Therefore, reasonable and effective evaluation is the compass of language teaching reform practice, has the important test and the instruction function to the language teaching. One of the most widely recognized evaluation methods in the educational circles is the formative assessment. In PBL and multimedia combination teaching mode can be more scientific and comprehensive auxiliary form assessment carried out, each problem is assigned by the teacher will leave traces in the multimedia network to sum up is for language learners to grasp the situation of an effective assessment. The characteristics of this approach is that the students' learning achievements in each stage are recorded, which really reflects the true performance of students in nursing English learning.

\section{Effects of Nursing Students' Learning English Based on PBL}

Arouse Learning Interest. Nursing students often attach importance to the professional courses learning and ignoring the English learning. An important reason for the phenomenon is the lack of interest in learning. Students need to make full use of the existing language resources. Traditional 
nursing English teaching content has nothing with the students' professional courses. Therefore, students learning English in addition to deal with all kinds of exams, seems to be useless. Students' thinking is a simple thinking of examination. This obstacle has a very clear performance. Obviously, it is difficult to motivate and maintain the students' learning interest, and the students' English level is also very difficult to get a substantial improvement. In this paper, the purpose of the study is to enhance the task of high cognitive requirements by introducing the PBI teaching method. These tasks have direct contact with medical students. Students need to cooperate to solve the problem, in the process of fully mobilize the knowledge reserve. Thus, the students' learning behaviors change from passive reception to active exploration. The English learning interest has been promoted based on PBL.

Improve English Ability. Due to different clinical and nursing requirements of different subject, teachers should pay attention to guiding students on the basic concept and theory of the master to master knowledge context. The design should inspire students to foreign nurses' identity conversion and evaluate the nursing of the patients, nursing and health education. For students, the PBL method is a new learning mode, and it is also a new teaching mode for teachers. PBL method to cultivate students' autonomous learning and thinking as the goal, to cultivate the students "how to learn new knowledge; students for empathy on the problem to solve the problem as the mission, from the bottom of my heart attach importance to do their own thing, can fully think of, and use their wisdom; to strengthen the English knowledge and clinical nursing aspect to contact and deepened understanding of knowledge and consolidate. PBL has obvious advantages in the learning interest, self-learning ability. According to the students' evaluation of PBL, the evaluation of the learning effects of clinical English teaching is satisfactory, and the students' English abilities are improved.

Expand Communication Channels. English training can encourage nursing students constantly to improve themselves and show their own comprehensive quality, which is conducive to the management talent scout and orientation training. It help our country to store professional nursing English talents, build bridge for foreign exchange laid the social basis of development and medical service internationalization to nurse the newer and higher requirements, English training is carrying out the continue nursing education, improve the nurses comprehensive quality and one of the ways to adapt to the new century has entrusted to the nurse's multiple roles, in the training of the comprehensive quality of nurses, also need us to further change ideas, tireless exploration of theory and practice. Support nurses to participate in online forums with cancer care related organizations, to encourage the exchange activities of the International Association and professional interest groups. By taking part in the international exchange activities to make them feel the distinct nursing cultural differences, they exercise their image and appearance of the foreign exchange, enhance the ability of international cooperation and foreign exchange of self-confidence.

Reform Oral Teaching. In the traditional process of nursing English teaching, teachers often adopt the fill-in teaching methods and students can only listen to the teacher. It's a passive learning style, creating a large number of high “dumb English”. The nursing English teaching materials of medical colleges are mostly outdated content monotonous and boring, which cannot keep up with the speed of the development of nursing education. Strengthen practical English teaching, to improve the practical ability in English, has become nursing English teaching reform in a new round of reform is an important issue in this study is on the traditional model of a challenge, on the basis of traditional teaching, pay more attention to the diversification of teaching form. The usefulness of the flexibility of PBL teaching method and teaching content from the quality of clinical oral English training feedback, satisfactory results indicated that the curriculum design is reasonable in clinical nursing practice oral English learning provides the significance of scientific practice. English academic promotion team training is to improve the professional English oral and written communication skills of nursing staff, effective training methods, can provide reference for clinical nursing staff English training mode. Foreign patients in emergency treatment, after the PBL learning of nursing staff not only understand each other's intentions, but also fluent in oral English communication. Nursing students can provide good services in the triage, registration, examination, treatment stages by oral English for the foreign patients. 


\section{Conclusion}

The PBL method can not only cultivate students' independent ability, innovation ability and the problem-solving ability, but also stimulate the students' ' interest and improve their English level. It highlights the purpose of English learning, focusing on cultivating students' ability to use English to solve practical problems in medical services. The use of PBL mode in the English teaching of nursing major is a new and beneficial attempt for the reform of medical English education.

\section{References}

[1] Yang Lin, Li Guangwei, Zhu Lili, Application of PBL Combined with Multimedia Teaching Modern Nursing English Teaching, China Journal of Pharmaceutical Economics, 2014(7): 22-204.

[2] He Yang, Wei Li, Research on the teaching practice of applying PBL and including EMP in college English teaching, Journal of Jining Medical University, 2013, 36(1): 66-69.

[3] Shi Chen, Liu Ying, Ji Jinli, Application of PBL in Medical English Teaching, Northwest Medical Education, 2011, 19(3): 594-596.

[4] Chang Zongxia, Yuan Wei, Yang Guihua, Jiao Linlin, Application of PBL teaching method in the training for clinical nursing staff on professional English ability, Journal of Qilu Nursing, 2014, 20(11): 25-27. 